\title{
Room Temperature Ferromagnetic and Optical Properties of Chrome Doped ZnS Nanorods Prepared by Hydrothermal Method
}

\author{
Wenhua Zhao, ${ }^{1,2}$ Zhiqiang Wei, ${ }^{1,2}$ Li Zhang, ${ }^{1}$ Xiaojuan Wu, ${ }^{1,2}$ \\ Xuan Wang, ${ }^{2}$ and Jinlong Jiang ${ }^{2}$ \\ ${ }^{1}$ State Key Laboratory of Advanced Processing and Recycling Nonferrous Metals, Lanzhou University of Technology, \\ Lanzhou 730050, China \\ ${ }^{2}$ School of Science, Lanzhou University of Technology, Lanzhou 730050, China
}

Correspondence should be addressed to Zhiqiang Wei; qianweizuo@163.com

Received 24 December 2016; Accepted 27 February 2017; Published 27 March 2017

Academic Editor: Biswanath Bhoi

Copyright (c) 2017 Wenhua Zhao et al. This is an open access article distributed under the Creative Commons Attribution License, which permits unrestricted use, distribution, and reproduction in any medium, provided the original work is properly cited.

Cr doped $\mathrm{Zn}_{1-x} \mathrm{Cr}_{x} \mathrm{~S}$ nanorods with different concentration ratio $(x=0,0.01,0.03$, and 0.05$)$ were successfully synthesized by hydrothermal method. The crystal microstructure, morphology, chemical composition, and optical and magnetic properties of the samples were characterized by X-ray diffraction (XRD), field-emission scanning electron microscopy (FESEM), high-resolution transmission electron microscopy (HRTEM), X-ray energy dispersive spectrometry (XEDS), diffuse-reflectance spectroscopy (DRS), photoluminescence (PL) spectra, and the vibrating sample magnetometer (VSM). All the samples synthesized by this method exhibited single-phase wurtzite structure with good crystallization as demonstrated by XRD studies, which indicated that all $\mathrm{Cr}$ ions successfully substituted for the lattice site of $\mathrm{Zn}^{2+}$ and generated single-phase $\mathrm{Zn}_{1-x} \mathrm{Cr}_{x} \mathrm{~S}$. DRS revealed the band gap of doped $\mathrm{Zn}_{1-x} \mathrm{Cr}_{x} \mathrm{~S}$ underwent blue shift compared to that of the bulk $\mathrm{ZnS}$. PL spectra showed obvious ultraviolet emission peak at $375 \mathrm{~nm}$ and two blue emissions appear about 500 and $580 \mathrm{~nm}$. The blue emissions intensity of doped samples improved with the increase of $\mathrm{Cr}$ concentration, comparing to pure $\mathrm{ZnS}$. Magnetic measurements indicated that the undoped and doped $\mathrm{ZnS}$ nanorods exhibited well-defined ferromagnetic behavior at room temperature. The saturation magnetization weakened significantly with increasing $\mathrm{Cr}$ concentration comparing to pure $\mathrm{ZnS}$ and reached minimum for $3 \% \mathrm{Cr}$.

\section{Introduction}

Diluted magnetic semiconductors (DMS) are referred to as nonmagnetic semiconductors in which a small fraction of host cations are replaced by transition metal or rare-earth ions, with both spin and charge degrees of freedom in a single material [1]. DMS has attracted enormous interest due to the exchange interactions between the spins of the dopant atoms and the carriers in the semiconductor host, as they are expected to bring global ferromagnetic order in the entire lattice at room temperature. $\mathrm{ZnS}$ is a kind of the II-VI semiconductor materials with direct wide band gap energy $(3.7 \mathrm{eV})$, and it is a versatile and multifunctional semiconductor material, which has good piezoelectric, ferromagnetic, photoelectric, and photosensitive properties [2,3]. The investigations for ZnS diluted magnetic semiconductor (DMS) nanocrystals have attracted considerable attention due to their novel properties and broad application prospect in diverse areas, such as spin-polarized light emitting diode, spin field-effect transistors, field-emission devices, optical isolator, and quantum computer [4-8].

In recent years, single transition metal doped $\mathrm{ZnS}$ have been extensively investigated by various methods, and the electrical, magnetic, and optical properties of $\mathrm{ZnS}$ can be modified by controlling the preparation process, changing the kinds of doping elements and doping amount. Transition metals (TMs) (e.g., Nd [9], Mn [10], Co [11], Cu [12], Fe [13], and $\mathrm{Ni}$ [14-16]) doped $\mathrm{ZnS}$ based diluted magnetic 
semiconductors (DMS) are potential candidate for luminescent properties and room temperature ferromagnetism. Many experimental results have observed the room temperature ferromagnetism (RTFM) and extraordinary photoluminescence $(\mathrm{PL})$ primarily depending on the synthesis method as well as processing conditions [17-19]. But, to the best of our knowledge, there are no reports on the effect of the structural, optical, and magnetic properties for $\mathrm{Cr}$ doped $\mathrm{ZnS}$ nanorods.

Hence, the understanding of FM origination in $\mathrm{Cr}$ doped $\mathrm{ZnS}$ nanorods is still in urgent demand.

In the present work, undoped and $\mathrm{Cr}$ doped $\mathrm{ZnS}$ nanorods were synthesized by hydrothermal method using ethylenediamine as modifier. The samples were characterized by X-ray diffraction (XRD), field-emission scanning electron microscopy (FESEM), high-resolution transmission electron microscopy (HRTEM), X-ray energy dispersive spectrometry (XEDS), diffuse-reflectance spectroscopy (DRS), photoluminescence (PL) spectra, and the vibrating sample magnetometer (VSM) to investigate the crystal microstructure, morphology, constituent elements, and optical and magnetic properties.

\section{Materials and Methods}

$\mathrm{Zn}_{1-x} \mathrm{Cr}_{x} \mathrm{~S}$ nanorods $(x=0,0.01,0.03$, and 0.05$)$ were successfully synthesized by hydrothermal method. All raw materials used in this work were of analytical grade and without further purification. In the synthesis process, a required amount of ethylenediamine $\left(\mathrm{C}_{2} \mathrm{H}_{8} \mathrm{~N}_{2}\right)$ was dissolved in deionized water. Meanwhile, weighed zinc acetate $\left(\mathrm{Zn}\left(\mathrm{CH}_{3} \mathrm{COO}\right)_{2} \cdot 2 \mathrm{H}_{2} \mathrm{O}\right)$ and chrome chloride $\left(\mathrm{CrCl}_{3} \cdot 6 \mathrm{H}_{2} \mathrm{O}\right)$ according to the chemical formula and the mole ratio of the metal cation of undoped $\mathrm{ZnS}$ and $\mathrm{Cr}$ doped $\mathrm{ZnS}$ mixed together and dissolved into the mixed solvent to obtain a solution of $0.015 \mathrm{~mol} / \mathrm{L}$. Then a certain amount of thiourea $\left(\mathrm{NH}_{2}\right)_{2} \mathrm{CS}$ was added to the above solution, and the mixture was magnetically stirred at room temperature for $30 \mathrm{~min}$. Finally, the prepared solution was transferred into a $100 \mathrm{ml}$ Teflon lined stainless steel autoclave, and the hydrothermal synthesis was heated at $200^{\circ} \mathrm{C}$ for $12 \mathrm{~h}$ in an oven and then cooled to room temperature naturally. Thereafter, the resulting precipitate was separated centrifugally and washed with distilled water and absolute alcohol several times, respectively. The obtained products were dried in oven at $60^{\circ} \mathrm{C}$ for $10 \mathrm{~h}$. Thus, $\mathrm{Zn}_{1-x} \mathrm{Cr}_{x} \mathrm{~S}$ nanocrystals were collected and used for further studies.

The structural analysis of as-synthesized samples was examined by a powder X-ray diffractometer (Japan Rigaku $\mathrm{D} / \mathrm{Max}-2400)$ with $\mathrm{CuKa}$ radiation at $\lambda=1.54056 \AA$. The samples were scanned in the angular range from 10 to $90^{\circ}$ $(2 \theta)$ with scanning rate $0.005^{\circ} / \mathrm{s}$ and step size $0.02^{\circ}$. The average crystalline grain size of the products was estimated from the half maximum width and the peak position of an XRD line broadened according the Scherrer formula. The morphology and microstructure of the samples were observed by field-emission scanning electron microscope (FESEM, 200 FEG) and high-resolution transmission electron microscopy (HRTEM, JEM-2010). The chemical composition of the products was verified by X-ray energy

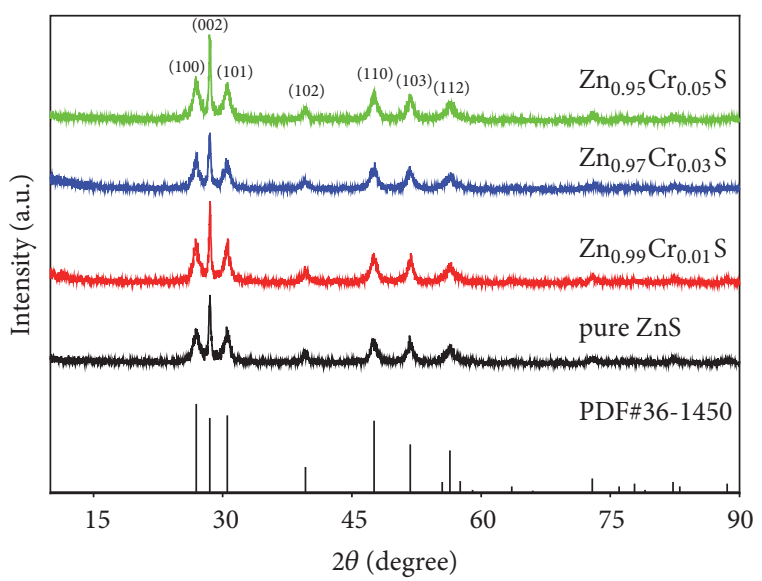

FIGURE 1: XRD patterns of $\mathrm{Zn}_{1-x} \mathrm{Cr}_{x} \mathrm{~S}(x=0,0.01,0.03$, and 0.05$)$ nanorods.

dispersive spectroscopy (XEDS) at an acceleration voltage of $200 \mathrm{keV}$ in TEM. The optical properties of the samples were analyzed using ultraviolet-visible (UV-VIS, TU-1901) spectrophotometer. Photoluminescence (PL) spectra were recorded on a PerkinElmer fluorescence spectrometer with the excitation wavelength of $320 \mathrm{~nm}$. Magnetic hysteresis loops were investigated at room temperature using a vibrating sample magnetometer (VSM, Lakeshore 7304) with an applied field from -8000 Oe to 8000 Oe.

\section{Results and Discussion}

3.1. Structural Analysis. The XRD patterns of different doping concentration ratio $\mathrm{Zn}_{1-x} \mathrm{Cr}_{x} \mathrm{~S}(x=0.01,0.03$, and 0.05$)$ nanorods compared with pure $\mathrm{ZnS}$ are shown in Figure 1. It is obvious that the diffraction peaks located at $2 \theta=26.91^{\circ}$, $28.50^{\circ}, 30.53^{\circ}, 39.61^{\circ}, 47.56^{\circ}, 51.78^{\circ}$, and $56.39^{\circ}$ correspond to (100), (002), (101), (102), (110), (103), and (112) planes, respectively. All the diffraction peaks can be well indexed with the single-phase hexagonal wurtzite $\mathrm{ZnS}$ structure, which are readily matched with the standard spectrum (JCPDS 361450). In addition, no extra diffraction peaks assigned to other secondary phases such as metal clusters or metal oxides are detected from the XRD patterns, which confirms that the samples are pure single phase. Thus, it indicates that $\mathrm{Cr}^{3+}$ is effectively substituted into $\mathrm{Zn}^{2+}$ ions sites within the $\mathrm{ZnS}$ crystal lattice without changing the wurtzite structure of the parent $\mathrm{ZnS}$.

Based on the XRD results, the average crystalline size of pure $\mathrm{ZnS}$ and doped $\mathrm{ZnS}$ nanorods can be calculated from the full width at half maximum (FWHM) of the most intense diffraction peak (002) according to Scherrer formula as follows: $D=K \lambda / B \cos \theta$, where $D$ represents the average crystalline size, $K=0.89$ is the Scherrer constant, $\lambda$ is $\mathrm{X}$-ray wavelength ( $\mathrm{Cu} \mathrm{Ka}, 1.54056 \AA$ ), $\theta$ is the diffraction angle, and $B$ is FWHM of (002) diffraction peak in radians. The (002) diffraction peak FWHM of pure $\mathrm{ZnS}$ is greater than that of doped $\mathrm{ZnS}$ samples, which is indicating the incorporation of dopant ions as substituents in the lattice of the host material. It is evident that the increase slightly 

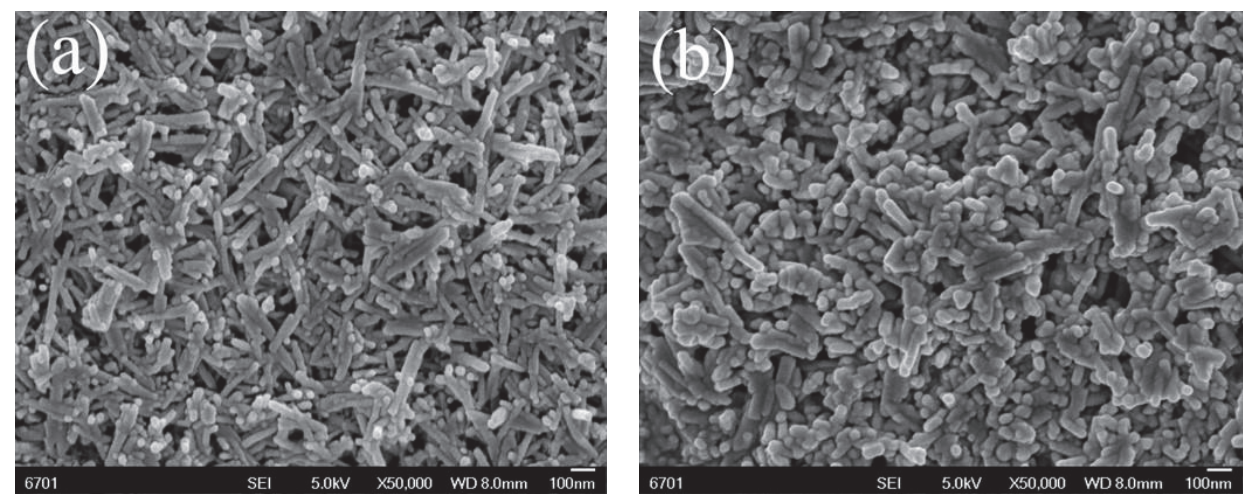

FIGURE 2: FESEM images of (a) pure $\mathrm{ZnS}$ and (b) $\mathrm{Zn}_{0.95} \mathrm{Cr}_{0.05} \mathrm{~S}$ nanorods.

TABLE 1: Parameters of the XRD patterns for $\mathrm{Zn}_{1-x} \mathrm{Cr}_{x} \mathrm{~S}(x=0,0.01,0.03$, and 0.05$)$ nanorods.

\begin{tabular}{lccccccc}
\hline Sample & $2 \theta\left(^{\circ}\right)$ & FWHM $\left(^{\circ}\right)$ & $d_{h k l}(\AA)$ & $a(\AA)$ & $c(\AA)$ & Cell volume $\left(\AA^{3}\right)$ & $D(\mathrm{~nm})$ \\
\hline Pure $\mathrm{ZnS}$ & 28.500 & 0.269 & 3.129 & 3.829 & 6.258 & 79.45 & 30 \\
$\mathrm{Zn}_{0.99} \mathrm{Cr}_{0.01} \mathrm{~S}$ & 28.520 & 0.213 & 3.127 & 3.828 & 6.254 & 39.36 & 77.90 \\
$\mathrm{Zn}_{0.97} \mathrm{Cr}_{0.03} \mathrm{~S}$ & 28.618 & 0.245 & 3.117 & 3.799 & 6.233 & 36 \\
$\mathrm{Zn}_{0.95} \mathrm{Cr}_{0.05} \mathrm{~S}$ & 28.539 & 0.258 & 3.125 & 3.824 & 6.250 & 79.15 & 39 \\
\hline
\end{tabular}

of FWHM with increasing $\mathrm{Cr}$ dopant concentration is in turn increase of the crystallite size. Comparing the doped samples and pure $\mathrm{ZnS}$, the results suggest that the doping concentration influences the crystallites size.

The corresponding parameters of the main diffraction peak (002) for undoped $\mathrm{ZnS}$ and $\mathrm{Cr}$ doped $\mathrm{ZnS}$ samples are listed in Table 1 . The (002) diffraction peak position for $\mathrm{Zn}_{1-x} \mathrm{Cr}_{x} \mathrm{~S}$ samples evidently shifts to higher angle, comparing to pure $\mathrm{ZnS}$. In addition, the peak positions of synthesized $\mathrm{Zn}_{1-x} \mathrm{Cr}_{x} \mathrm{~S}$ nanorods shift to higher angles with the concentration of $\mathrm{Cr}$ doping increasing. When there is a small amount of $\mathrm{Cr}$ doping $(x=0.03)$, the diffraction peak position of the doped $\mathrm{ZnS}$ nanorods reaches maximum. Shift of peak position towards higher angle is explained from lattice constant shrinkage, which is attributed to the substitution of the $\mathrm{Zn}^{2+}$ ions by the smaller $\mathrm{Cr}^{3+}$ ions. According to the Bragg formula: $2 d_{h k l} \sin \theta=\lambda$, where $d_{h k l}$ denotes the crystalline plane distance for indices $(h k l)$ and $\theta$ is the diffraction angle of the (002) peak. Plainly, the decrease of the crystalline plane distances will result in the increase of the diffraction angles. From Table 1, it can be found that $d$ values of pure $\mathrm{ZnS}$ are greater than that of doped $\mathrm{ZnS}$ samples, while $d$ value of doped samples decrease with the increase of $\mathrm{Cr}$ doped content. The lattice constants $a$ and $c$ are calculated by the following formula: $a=d_{h k l} \sqrt{(4 / 3)\left(h^{2}+h k+l^{2}\right)+(a / c)^{2} l^{2}}$, the lattice constant $a$ is obtained for the (100) plane through the relation $a=$ $\lambda / \sqrt{3} \sin \theta$, and the lattice constant $c$ is derived for the (002) plane using the relation $c=\lambda / \sin \theta$, respectively. The calculation results are given in Table 1. The lattice constants of the doped $\mathrm{ZnS}$ are smaller than that of pure $\mathrm{ZnS}$, and the lattice constants $a$ and $c$ and their interplanar distance of doped $\mathrm{ZnS}$ decrease with the increase of $\mathrm{Cr}$ doped content, reaching minimum for $3 \% \mathrm{Cr}$. It can be attributed that the ionic radius of the $\mathrm{Cr}^{3+}(0.69 \AA)$ is smaller than that of the $\mathrm{Zn}^{2+}(0.74 \AA)$, which revealed that $\mathrm{Cr}$ ions occupy $\mathrm{Zn}$ ions sites in the wurtzite structure, causing lattice distortion [20].

The volume of unit cell of hexagonal system is evaluated from equation: $V=\sqrt{3} a^{2} c / 2=0.866 a^{2} c$. As the doping concentration is increasing, the volume of the unit cell of the doped nanorods dramatically decreases comparing to pure $\mathrm{ZnS}$. When there is a small amount of Cr doping $(x=0.03)$, the volume of the unit cell of the doped nanorods reaches maximum, which is shown in Table 1. It indicates that the changes in peak position, peak width, and peak intensity depend on the lattice parameter and cell volume, which is mainly attributed to the successful incorporation of $\mathrm{Cr}^{3+}$ ions into $\mathrm{ZnS}$ lattice.

3.2. Morphological Studies. The morphology of pure $\mathrm{ZnS}$ and doped ZnS samples is studied by FESEM and HRTEM. Figure 2 shows the FESEM images of the undoped $\mathrm{ZnS}$ and $\mathrm{Zn}_{0.95} \mathrm{Cr}_{0.05} \mathrm{~S}$ samples, respectively. Figure 2(a) shows FESEM images of undoped $\mathrm{ZnS}$ sample, and it is observed that pure $\mathrm{ZnS}$ nanorods possess one-dimensional rod-like shape. The diameter of the samples ranges from 30 to $40 \mathrm{~nm}$, with an average diameter approximately $30 \mathrm{~nm}$ and the length about 200-300 $\mathrm{nm}$. The micrograph clearly indicates the presence of weak aggregation between the rods. Figure 2(b) shows the FESEM micrograph of $\mathrm{Zn}_{0.95} \mathrm{Cr}_{0.05} \mathrm{~S}$ sample, which shows the presence of large roughly one-dimensional rod-like structure with regular length distribution. $\mathrm{Cr}$ doped $\mathrm{ZnS}$ system does not change the morphology of the samples, but the diameter slightly increases and the length decreases with the increase 

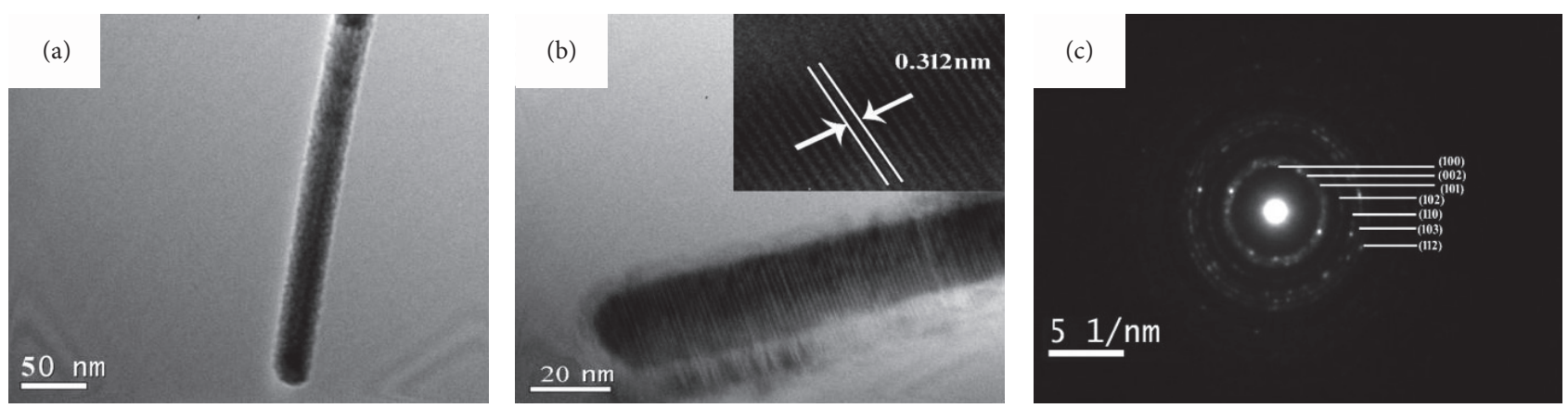

FIGURE 3: HRTEM micrographs and SAED patterns of $\mathrm{Zn}_{0.95} \mathrm{Cr}_{0.05} \mathrm{~S}$.

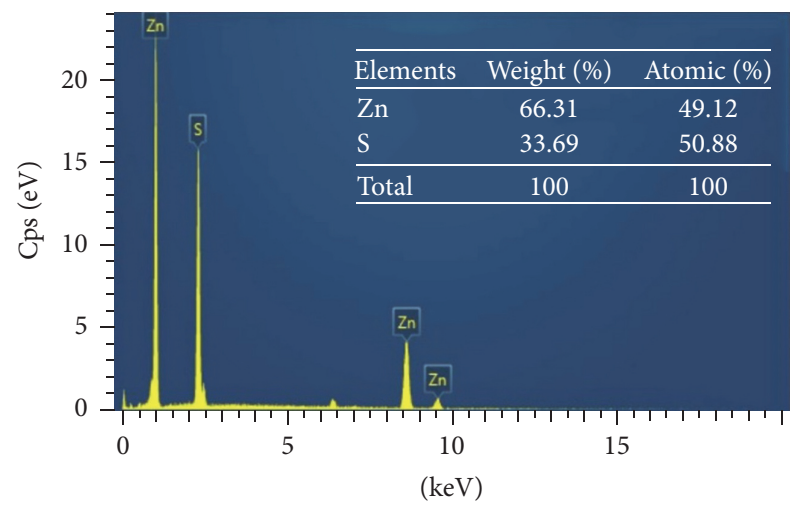

(a)

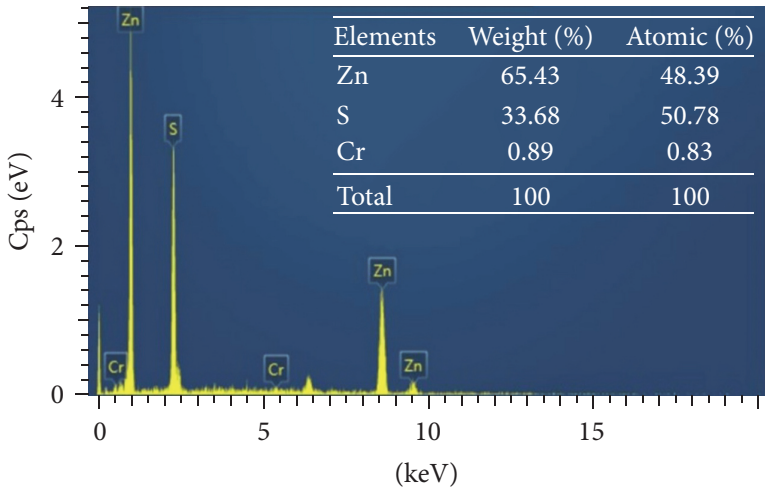

(b)

FIGURE 4: XEDS patterns of pure $\mathrm{ZnS}$ (a) and $\mathrm{Zn}_{0.95} \mathrm{Cr}_{0.05} \mathrm{~S}$ (b).

of $\mathrm{Cr}$ concentration. From the above observations, it can be noticed that the doping concentration of $\mathrm{Cr}$ affects the parent $\mathrm{ZnS}$, and the nanorods are in the nanoscale region. Comparing with pure $\mathrm{ZnS}$ samples, the morphology of doped samples becomes shorter and wider, and the rod length diameter ratio becomes lower.

Figure 3 displays the HRTEM micrographs of $\mathrm{Zn}_{0.95} \mathrm{Cr}_{0.05} \mathrm{~S}$ sample. From this figure, it can be found that $\mathrm{Zn}_{0.95} \mathrm{Cr}_{0.05} \mathrm{~S}$ nanorods are the same as the FESEM images, possessing roughly one-dimensional rod-like structure and well dispersed with clear edge and smooth surface. The average diameter of the nanorods is about $30 \mathrm{~nm}$, and the length ranges from 200 to $300 \mathrm{~nm}$. Figure 3(b) displays the typical HRTEM image of $\mathrm{Zn}_{0.95} \mathrm{Cr}_{0.05} \mathrm{~S}$ nanorods, and it reveals the clear lattice fringe, with no obvious defects. The interplanar distance is about $0.312 \mathrm{~nm}$, which is in good agreement with the $d$-spacing of (002) plane of hexagonal wurtzite $\mathrm{ZnS}$ structure. The value of lattice spacing is smaller than that of bulk $\mathrm{ZnS}$, and the crystal lattice has tendency to shrink, which can be attributed to the difference of ion radius of $\mathrm{Zn}^{2+}(0.74 \AA)$ comparing with that of $\mathrm{Cr}^{3+}$ $(0.69 \AA)$. Therefore, it is evident that $\mathrm{Cr}$ doping influences the morphology of the samples. The HRTEM analysis is in good agreement with the FESEM and XRD results, which further indicates that all $\mathrm{Cr}^{3+}$ successfully substituted for the lattice site of $\mathrm{Zn}^{2+}$ and generated single-phase $\mathrm{Zn}_{1-x} \mathrm{Cr}_{x} \mathrm{~S}$ [21].
The corresponding selected area electron diffraction (SAED) patterns of $\mathrm{Zn}_{0.95} \mathrm{Cr}_{0.05} \mathrm{~S}$ sample are shown in Figure 3(c), and the SAED pattern consists of many regular diffraction rings with different radius and one center. These rings correspond to (100), (002), (101), (102), (110), (103), and (112) planes of $\mathrm{Zn}_{0.95} \mathrm{Cr}_{0.05} \mathrm{~S}$ nanorods from inner to exterior, respectively. The SAED pattern also confirms that $\mathrm{Zn}_{0.95} \mathrm{Cr}_{0.05} \mathrm{~S}$ nanorods are wurtzite structure, belonging to polycrystalline structure, which is in agreement with the result of XRD. It indicates that the $\mathrm{Cr}^{3+}$ ions do not degrade the crystallinity of $\mathrm{ZnS}$ nanorods.

3.3. Chemical Characterization. In order to confirm the existence of the $\mathrm{Cr}$ elements of the doped samples, XEDS analysis is recorded. Figure 4 shows the XEDS patterns of the undoped $\mathrm{ZnS}$ and $\mathrm{Zn}_{0.92} \mathrm{Cr}_{0.05} \mathrm{~S}$ nanorods. From Figure 4(a), it can be found that the undoped $\mathrm{ZnS}$ nanorods mainly contain S and Zn two elements. Figure 4(b) obviously confirms the presence of $\mathrm{Cr}$ elements besides $\mathrm{S}$ and $\mathrm{Zn}$ elements for $\mathrm{Zn}_{0.95} \mathrm{Cr}_{0.05} \mathrm{~S}$ nanorods, whereas the spectrum of pure $\mathrm{ZnS}$ did not find the presence of $\mathrm{Cr}$ elements. The quantitative atomic and weight percentage of the compositional elements are indicated in the inset of Figure 4. The calculated weight and atomic percentage are nearly equal to their nominal stoichiometry within the experimental error. The XEDS results further verify XRD conclusion, which indicates that 


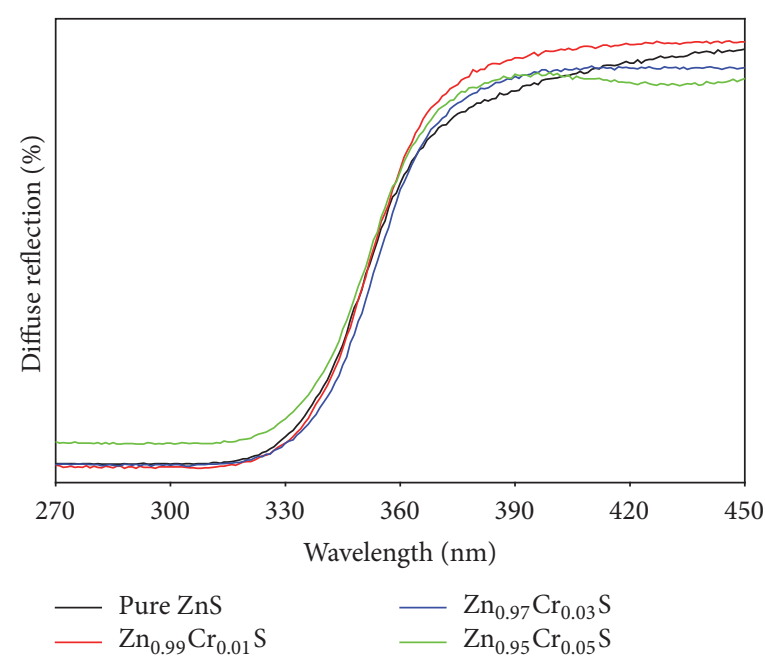

(a)

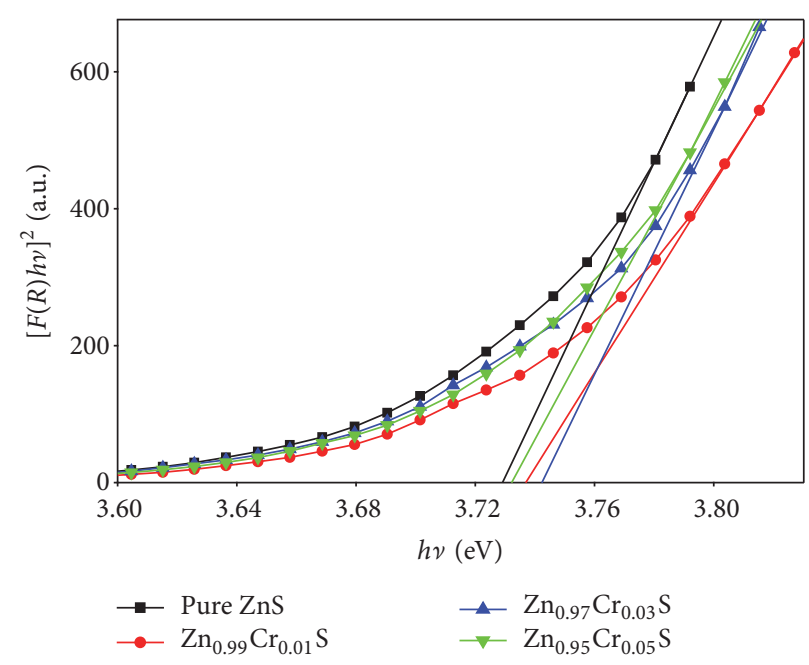

(b)

FIGURE 5: UV-Vis diffuse-reflectance spectra $(\mathrm{a})$ and $(F(R) h v)^{2}$ versus $h \nu$ curves $(\mathrm{b})$ of $\mathrm{Zn}_{1-x} \mathrm{Cr}_{x} \mathrm{~S}(x=0,0.01,0.03$, and 0.05$)$ nanorods.

TABLE 2: Band gap and magnetic moments of $\mathrm{Zn}_{1-x} \mathrm{Cr}_{x} \mathrm{~S}(x=0,0.01,0.03$, and 0.05$)$ nanorods.

\begin{tabular}{lcccc}
\hline Sample & Band gap $(\mathrm{eV})$ & Saturation magnetization & $\begin{array}{c}\text { Magnetic moments (emu/g) } \\
\text { Remanent magnetization }\left(10^{-4}\right)\end{array}$ & Coercivity (Oe) \\
\hline Pure $\mathrm{ZnS}$ & 3.729 & 0.0117 & 6.415 & 46.71 \\
$\mathrm{Zn}_{0.99} \mathrm{Cr}_{0.01} \mathrm{~S}$ & 3.737 & 0.0111 & 5.122 & 40.26 \\
$\mathrm{Zn}_{0.97} \mathrm{Cr}_{0.03} \mathrm{~S}$ & 3.743 & 0.0097 & 5.339 & 41.22 \\
$\mathrm{Zn}_{0.95} \mathrm{Cr}_{0.05} \mathrm{~S}$ & 3.732 & 0.0105 & 5.376 & 42.74 \\
\hline
\end{tabular}

Cr doped ZnS diluted magnetic semiconductors are successfully synthesized by hydrothermal method, and $\mathrm{Cr}^{3+}$ are successfully substituted as dopant in $\mathrm{ZnS}$ matrix.

3.4. Optical Properties. The diffuse-reflectance spectra are employed to investigate the effect of $\mathrm{Cr}$ doping on the optical characteristics of $\mathrm{Zn}_{1-x} \mathrm{Cr}_{x} \mathrm{~S}$ nanorods. The DRS of the pure $\mathrm{ZnS}$ and doped $\mathrm{ZnS}$ nanorods are depicted in Figure 5(a). The characteristic absorption edges band at ultraviolet (UV) region lies in the range of 330-390 nm, which shows that all samples possess wide absorption. The absorption coefficients are different, and there is an effect on the position of the absorption peaks. For analysis purposes the diffusereflectance $(R)$ of the sample can be related to the KubelkaMunk function $F(R)$ by the relation $F(R)=(1-R)^{2} / 2 R$. The band gap of the $\mathrm{Zn}_{1-x} \mathrm{Cr}_{x} \mathrm{~S}$ nanorods is estimated from the diffuse-reflectance spectra by plotting the square of the Kubelka-Munk function $F(R)^{2}$ versus energy and extrapolating the linear part of the curve to $F(R)^{2}=0$, which is shown in Figure 5(b). The absorption edges for $\mathrm{Zn}_{1-x} \mathrm{Cr}_{x} \mathrm{~S}$ samples are seen to be evidently shifted towards lower wavelengths comparing with pure $\mathrm{ZnS}$ and are shown in Figure 5(b). The measured values of optical band gap energy for pure $\mathrm{ZnS}$ are showed in Table 2, and $\mathrm{Zn}_{0.99} \mathrm{Cr}_{0.01} \mathrm{~S}, \mathrm{Zn}_{0.97} \mathrm{Cr}_{0.03} \mathrm{~S}$, and $\mathrm{Zn}_{0.95} \mathrm{Cr}_{0.05} \mathrm{~S}$ are $3.729 \mathrm{eV}, 3.737 \mathrm{eV}, 3.743 \mathrm{eV}$, and $3.732 \mathrm{eV}$, respectively, which indicates that the $\mathrm{Cr}$ ions replace the $\mathrm{Zn}$ ions in the $\mathrm{ZnS}$ lattice, and the band gap of $\mathrm{Cr}$ doped $\mathrm{ZnS}$ samples is greater than that of pure $\mathrm{ZnS}$. The band gap energy gradually increases with the increase of $\mathrm{Cr}$ concentration, up to a maximum $3.743 \mathrm{eV}$ for $3 \%$ Cr. Furthermore, the band gap values estimated for these samples are in the range of $3.729-3.743 \mathrm{eV}$ that are slightly greater than that of bulk $\mathrm{ZnS}$ $(3.7 \mathrm{eV})$, which is manifested in the fact that the band gap energy undergoes blue shift in the doped $\mathrm{ZnS}$ system. The increase in the band gap energy with the decrease in the lattice parameters $(a, c$, and $V$ ) is due to the effect of doping, which are strongly supported by XRD results and associated with the variation of the lattice parameters. It can be explained that the increase of optical band gap may be attributed to the sp- $\mathrm{d}$ spin-exchange interactions between the band electrons of host matrix and the localized d electrons of the transition metal ion substituting the captions. Thus, the s-d and p-d exchange interactions between the band electrons of $\mathrm{ZnS}$ and localized d electrons of $\mathrm{Cr}$ give rise to change in the energy band structure, which can increase the band gap.

PL spectra of pure $\mathrm{ZnS}$ and $\mathrm{Cr}$ doped $\mathrm{ZnS}$ nanorods are shown in Figure 6. It is observed that PL intensity of doped samples is higher than pure $\mathrm{ZnS}$ sample. The $\mathrm{ZnS}$ samples exhibit three obvious broad emission peaks at $375 \mathrm{~nm}$, $500 \mathrm{~nm}$, and $580 \mathrm{~nm}$, respectively. The obvious UV emission can be attributed to originate from excitonic recombination corresponding to the near-band-edge emission (NBE) of 


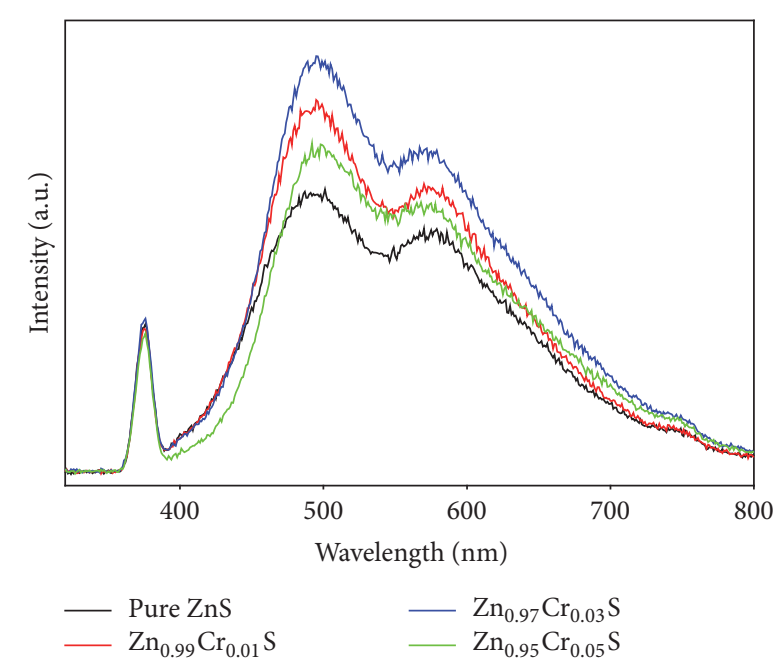

FIGURE 6: PL spectra of $\mathrm{Zn}_{1-x} \mathrm{Cr}_{x} \mathrm{~S}(x=0,0.01,0.03$, and 0.05) nanorods.

wide band gap of $\mathrm{ZnS}$ due to the quantum confinement effect [22]. The blue-green emission bands centered at $500 \mathrm{~nm}$ for samples may be attributed to $S$ vacancies in $\mathrm{ZnS}$ nanorods and $Z n$ vacancy related defects $[23,24]$. The green emission peak at $580 \mathrm{~nm}$ is possibly assigned to positively charged electron transition and surface traps mediated by defects in the band gap [25]. The origin of this peak is still not clear and needs further study.

The doped samples exhibit similar ultraviolet (UV) emission band at $375 \mathrm{~nm}$ to compare with pure $\mathrm{ZnS}$, which illustrates that the doped samples display nearly the same structure of pure $\mathrm{ZnS}$. As the doping concentration increases, the intensity of PL emission of the doped nanorods dramatically increases comparing to pure $\mathrm{ZnS}$. When there is a small amount of $\mathrm{Cr}$ doping $(x=0.03)$, the intensity of the peak of the PL spectrum reaches maximum. It is observed that the particle sizes of the doped samples increase with the increasing of $\mathrm{Cr}$ concentration from Table 1, which corresponds with XRD data. The increase in particle size results in enhanced surface defects leading to an increase in the PL intensity as chrome content is increased. It is because $\mathrm{Cr}^{3+}$ acts as a sensitizing agent and enhances the radiative recombination processes. Thus, the PL intensity of doped $\mathrm{Zn}_{1-x} \mathrm{Cr}_{x} \mathrm{~S}$ nanorods is higher than that of pure $\mathrm{ZnS}$ [26]. These results are in good agreement with XRD, EDX, and UVvisible studies.

3.5. Magnetic Studies. Figure 7 presents the RT magnetic hysteresis $(M-H)$ loops of the undoped $\mathrm{ZnS}$ and $\mathrm{Zn}_{1-x} \mathrm{Cr}_{x} \mathrm{~S}(x=$ $0.01,0.03$, and 0.05 ) nanorods measured with the applied magnetic field of $8 \mathrm{kOe}$. It has deducted the contributions from the diamagnetism of the Si substrate and the paramagnetism of the sample holder during VSM measurement. The $M-H$ curves show that all the samples exhibit obvious ferromagnetic behaviors. The ferromagnetism of undoped $\mathrm{ZnS}$ sample is attributed to the fact that sulfur vacancies boost both the emission and the magnetism, which is revealed $d 0$ ferromagnetism [27], and the stronger exchange interactions

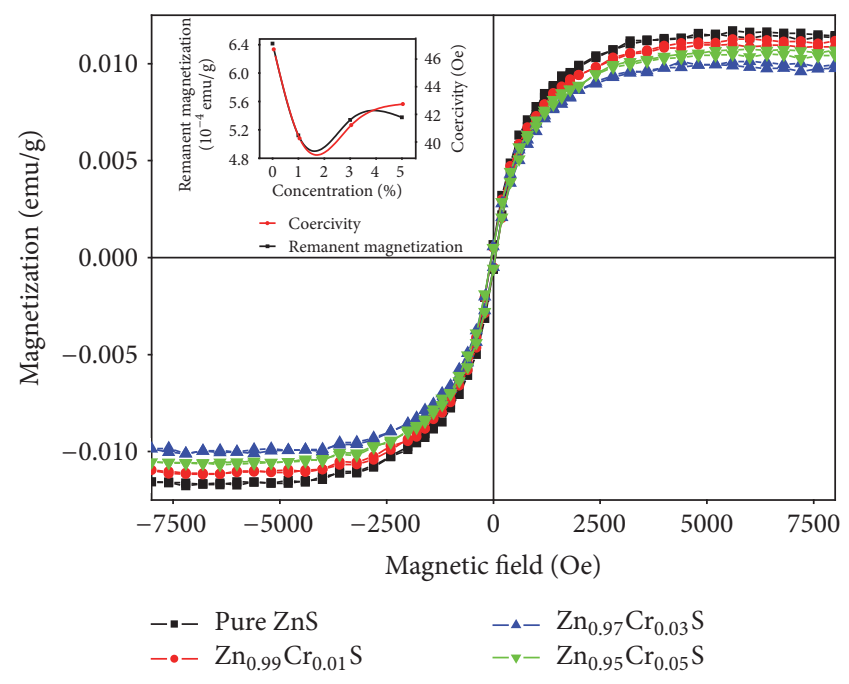

Figure 7: $M-H$ curves of $\mathrm{Zn}_{1-x} \mathrm{Cr}_{x} \mathrm{~S}(x=0,0.01,0.03$, and 0.05$)$ nanorods.

between these sulfur vacancies weakened the saturation magnetization (Ms). From XRD results of doped ZnS nanorods, it is suggested that there are no traces of impurity or secondary phases, thus removing the possibility of ferromagnetism due to the clusters of transition elements or secondary phases in the samples. Hence, the room temperature ferromagnetism of $\mathrm{Cr}$ doped $\mathrm{ZnS}$ samples could arise from intrinsic magnetic property.

The $M-H$ curves indicate the saturation magnetization values of $0.0117 \mathrm{emu} / \mathrm{g}, 0.0111 \mathrm{emu} / \mathrm{g}, 0.0097 \mathrm{emu} / \mathrm{g}$, and $0.0105 \mathrm{emu} / \mathrm{g}$ for pure $\mathrm{ZnS}, \mathrm{Zn}_{0.99} \mathrm{Cr}_{0.01} \mathrm{~S}, \mathrm{Zn}_{0.97} \mathrm{Cr}_{0.03} \mathrm{~S}$, and $\mathrm{Zn}_{0.95} \mathrm{Cr}_{0.05} \mathrm{~S}$ nanorods, respectively. In view of the $\mathrm{Cr}^{3+}$ ions substituted into $\mathrm{ZnS}$ lattice, the origin of magnetism in the samples is due to the exchange interaction between local spin-polarized electrons (such as the electrons of $\mathrm{Cr}^{3+}$ ions) and the conductive electrons. Such interaction can lead to the spin polarization of conductive electrons. Consequently, the spin-polarized conductive electrons undergo an exchange interaction with local spin-polarized electrons of other $\mathrm{Cr}^{3+}$ ions. Thus, after a successive long-range exchange interaction, almost all $\mathrm{Cr}^{3+}$ ions exhibit the same spin direction, resulting in the ferromagnetism of the material. Poornaprakash et al. also report [28] the magnetic property in $\mathrm{Cr}$ doped $\mathrm{ZnS}$ nanoparticles by hydrothermal method. Therefore, there is an increase in the intensity of the peak with increase in dopant content in that report.

The saturation magnetization of doped samples is smaller than that of pure $\mathrm{ZnS}$, and the values of saturation magnetization decrease with the increase of $\mathrm{Cr}$ doping concentration. It is interesting that the ferromagnetism is suppressed with the $\mathrm{Cr}$ concentration increasing. In addition, the saturation magnetization of $\mathrm{Zn}_{1-x} \mathrm{Cr}_{x} \mathrm{~S}$ samples decreases with the increase of $\mathrm{Cr}$ concentration comparing to pure $\mathrm{ZnS}$ and reaches minimum for $3 \% \mathrm{Cr}$. It is because the $\mathrm{Cr}^{3+}$ ions substitute the $\mathrm{Zn}$ ions, with the local hole concentration at the anion increasing. As the $\mathrm{Cr}$ concentration increases, the distance between the $\mathrm{Cr}$ atoms and each other is closer and the super 
exchange interaction between the neighboring $\mathrm{Cr}$ atoms is antiferromagnetic in nature. When there is an increase of $\mathrm{Cr}$ doping concentration, the enhanced antiferromagnetic interaction is attributed to the decreased volume and the ferromagnetic ordering is suppressed [29].

The variation of coercivity (Hc) and remanent magnetization (Mr) with $\mathrm{Cr}$ concentration of $\mathrm{Zn}_{1-x} \mathrm{Cr}_{x} \mathrm{~S}$ nanorods are indicated in the inset of Figure 7. It is observed that the values of $\mathrm{Ms}, \mathrm{Hc}$, and $\mathrm{Mr}$ of $\mathrm{Cr}$ doped $\mathrm{ZnS}$ samples are lower than that of pure $\mathrm{ZnS}$, respectively. In order to investigate the magnetic properties in $\mathrm{Zn}_{1-x} \mathrm{Cr}_{x} \mathrm{~S}$ nanorods clearly, the magnetic moments values are shown in Table 2. Furthermore, the $\mathrm{Hc}$ and $\mathrm{Mr}$ gradually increase in doped samples with the increase of $\mathrm{Cr}$ concentration. When $\mathrm{Hc}$ is smaller, the synthesized $\mathrm{ZnS}$ nanorods show soft magnetic properties.

\section{Conclusions}

(1) Pure $\mathrm{ZnS}$ and doped $\mathrm{Zn}_{1-x} \mathrm{Cr}_{x} \mathrm{~S}$ nanorods with different concentration ratio $(x=0,0.01,0.03$, and 0.05 ) were successfully synthesized by hydrothermal method. All the samples synthesized by this method exhibit single-phase wurtzite structure with good crystallization. All $\mathrm{Cr}$ ions successfully substituted for the lattice site of $\mathrm{Zn}^{2+}$ and generate single-phase $\mathrm{Zn}_{1-x} \mathrm{Cr}_{x} \mathrm{~S}$, the lattice constant underwent distortion, and the grain size increased with increasing $\mathrm{Cr}$ doping concentration. The morphology of all the samples is one-dimensional rod-like shape with good dispersion.

(2) The band gap of doped $\mathrm{Zn}_{1-x} \mathrm{Cr}_{x} \mathrm{~S}$ nanorods underwent blue shift compared to that of the bulk $\mathrm{ZnS}$. PL spectra show obvious ultraviolet emission peak at $375 \mathrm{~nm}$ and two blue emissions appear about 500 and $580 \mathrm{~nm}$, and the blue emissions intensity of doped samples improves with the increase of $\mathrm{Cr}$ concentration comparing to pure $\mathrm{ZnS}$ and reaches maximum for $3 \% \mathrm{Cr}$.

(3) Magnetic measurements indicate that the undoped and $\mathrm{Cr}$ doped $\mathrm{ZnS}$ samples exhibit ferromagnetic behavior at room temperature, and the saturation magnetization weakened significantly with increasing $\mathrm{Cr}$ concentration comparing to pure $\mathrm{ZnS}$ and reached minimum for $3 \% \mathrm{Cr}$. The variation of coercivity and remanent magnetization of $\mathrm{Cr}$ doped $\mathrm{ZnS}$ samples is lower than that of pure $\mathrm{ZnS}$, respectively. The $\mathrm{Hc}$ and $\mathrm{Mr}$ gradually increase with the increase of $\mathrm{Cr}$ concentration.

\section{Conflicts of Interest}

The authors declare that they have no conflicts of interest.

\section{Acknowledgments}

This work was supported by the National Natural Science Foundation of China (no. 51261015) and the Natural Science Foundation of Gansu Province, China (no. 1308RJZA238).

\section{References}

[1] D. Bui and V. Phan, "Ferromagnetic clusters induced by a nonmagnetic random disorder in diluted magnetic semiconductors," Annals of Physics, vol. 375, pp. 313-321, 2016.

[2] J. Cao, Q. Liu, D. Han et al., "Highly enhanced photocatalytic properties of $\mathrm{ZnS}$ nanowires-graphene nanocomposites," RSC Advances, vol. 4, no. 58, pp. 30798-30806, 2014.

[3] C.-J. Chang, K.-W. Chu, M.-H. Hsu, and C.-Y. Chen, "Nidoped $\mathrm{ZnS}$ decorated graphene composites with enhanced photocatalytic hydrogen-production performance," International Journal of Hydrogen Energy, vol. 40, no. 42, pp. 14498-14506, 2015.

[4] J.-Y. Kim, H. Kim, S. H. Park et al., "Effect of a critical percolation threshold in purified short carbon nanotubepolymer/ZnS:Cu,Cl composite on electroluminescence," Organic Electronics: Physics, Materials, Applications, vol. 13, no. 12, pp. 2959-2966, 2012.

[5] H. Haddad, A. Chelouche, D. Talantikite, H. Merzouk, F. Boudjouan, and D. Djouadi, "Effects of deposition time in chemically deposited ZnS films in acidic solution," Thin Solid Films, vol. 589, pp. 451-456, 2015.

[6] A. I. Inamdar, S. Cho, Y. Jo et al., "Optical properties in Mn-doped ZnS thin films: photoluminescence quenching," Materials Letters, vol. 163, pp. 126-129, 2016.

[7] M. J. Iqbal and S. Iqbal, "Synthesis of stable and highly luminescent beryllium and magnesium doped $\mathrm{ZnS}$ quantum dots suitable for design of photonic and sensor material," Journal of Luminescence, vol. 134, pp. 739-746, 2013.

[8] X. Xu, L. Hu, N. Gao et al., "Controlled growth from ZnS nanoparticles to ZnS-CdS nanoparticle hybrids with enhanced photoactivity," Advanced Functional Materials, vol. 25, no. 3, pp. 445-454, 2015.

[9] B. Poornaprakash, S. Ramu, S.-H. Park, R. P. Vijayalakshmi, and B. K. Reddy, "Room temperature ferromagnetism in Nd doped ZnS diluted magnetic semiconductor nanoparticles," Materials Letters, vol. 164, pp. 104-107, 2016.

[10] R. Nasser, H. Elhouichet, and M. Férid, "Effect of Mn doping on structural, optical and photocatalytic behaviors of hydrothermal Zn1-xMnxS nanocrystals," Applied Surface Science, vol. 351, pp. 1122-1130, 2015.

[11] L. Liu, L. Yang, Y. Pu, D. Xiao, and J. Zhu, "Optical properties of water-soluble $\mathrm{Co}^{2+}: \mathrm{ZnS}$ semiconductor nanocrystals synthesized by a hydrothermal process," Materials Letters, vol. 66, no. 1, pp. 121-124, 2012.

[12] W.-S. Ni and Y.-J. Lin, "Defect-induced magnetic properties of $\mathrm{Cu}$-doped $\mathrm{ZnS}$ films with different copper contents," Journal of Alloys and Compounds, vol. 649, pp. 968-972, 2015.

[13] D. Saikia, R. Raland, and J. P. Borah, "Influence of Fe doping on the structural, optical and magnetic properties of $\mathrm{ZnS}$ diluted magnetic semiconductor," Physica E: Low-Dimensional Systems and Nanostructures, vol. 83, pp. 56-63, 2016.

[14] G. Murugadoss and M. Rajesh Kumar, "Synthesis and optical properties of monodispersed Ni2+-doped ZnS nanoparticles," Applied Nanoscience, vol. 4, no. 1, pp. 67-75, 2014.

[15] S. Kumar and N. K. Verma, "Effect of Ni-doping on optical and magnetic properties of solvothermally synthesized $\mathrm{ZnS}$ wurtzite nanorods," Journal of Materials Science: Materials in Electronics, vol. 25, no. 2, pp. 785-790, 2014.

[16] J. Tang and K. L. Wang, "Electrical spin injection and transport in semiconductor nanowires: challenges, progress and perspectives," Nanoscale, vol. 7, no. 10, pp. 4325-4337, 2015. 
[17] C. Liu, D. Meng, H. Pang et al., "Influence of Fe-doping on the structural, optical and magnetic properties of $\mathrm{ZnO}$ nanoparticles," Journal of Magnetism and Magnetic Materials, vol. 324, no. 20, pp. 3356-3360, 2012.

[18] A. Goktas and İ. H. Mutlu, "Structural, optical, and magnetic properties of solution-processed co-doped ZnS thin films," Journal of Electronic Materials, vol. 45, no. 11, pp. 5709-5720, 2016.

[19] L.-J. Tang, G.-F. Huang, Y. Tian et al., "Efficient ultraviolet emission of ZnS nanospheres: co doping enhancement," Materials Letters, vol. 100, pp. 237-240, 2013.

[20] X. Wu, Z. Wei, L. Zhang, X. Wang, H. Yang, and J. Jiang, “Optical and magnetic properties of Fe doped $\mathrm{ZnO}$ nanoparticles obtained by hydrothermal synthesis," Journal of Nanomaterials, vol. 2014, Article ID 792102, 6 pages, 2014.

[21] X. Wu, Z. Wei, L. Zhang, C. Zhang, H. Yang, and J. Jiang, "Synthesis and characterization of $\mathrm{Fe}$ and $\mathrm{Ni}$ co-doped $\mathrm{ZnO}$ nanorods synthesized by a hydrothermal method," Ceramics International, vol. 40, no. 9, pp. 14635-14640, 2014.

[22] Z. Deng, J. Qi, Y. Zhang, Q. Liao, and Y. Huang, "Growth mechanism and optical properties of $\mathrm{ZnS}$ nanotetrapods," Nanotechnology, vol. 18, no. 47, Article ID 475603, 2007.

[23] S. Kar and S. Chaudhuri, "Synthesis and optical properties of single and bicrystalline ZnS nanoribbons," Chemical Physics Letters, vol. 414, no. 1-3, pp. 40-46, 2005.

[24] X. Zhang, Y. Zhang, Y. Song, Z. Wang, and D. Yu, "Optical properties of $\mathrm{ZnS}$ nanowires synthesized via simple physical evaporation," Physica E: Low-Dimensional Systems and Nanostructures, vol. 28, no. 1, pp. 1-6, 2005.

[25] Y.-C. Zhu, Y. Bando, and D.-F. Xue, "Spontaneous growth and luminescence of zinc sulfide nanobelts," Applied Physics Letters, vol. 82, no. 11, pp. 1769-1771, 2003.

[26] B. Poornaprakash, D. Amaranatha Reddy, G. Murali, N. Madhusudhana Rao, R. P. Vijayalakshmi, and B. K. Reddy, "Composition dependent room temperature ferromagnetism and PL intensity of cobalt doped ZnS nanoparticles," Journal of Alloys and Compounds, vol. 577, pp. 79-85, 2013.

[27] D. Gao, G. Yang, J. Zhang, Z. Zhu, M. Si, and D. Xue, "D0 ferromagnetism in undoped sphalerite ZnS nanoparticles," Applied Physics Letters, vol. 99, no. 5, Article ID 052502, 2011.

[28] B. Poornaprakash, K. Naveen Kumar, U. Chalapathi, M. Reddeppa, P. T. Poojitha, and S.-H. Park, "Chromium doped ZnS nanoparticles: chemical, structural, luminescence and magnetic studies," Journal of Materials Science: Materials in Electronics, vol. 27, no. 6, pp. 6474-6479, 2016.

[29] S. Sambasivam, D. Paul Joseph, J. G. Lin, and C. Venkateswaran, "Doping induced magnetism in Co-ZnS nanoparticles," Journal of Solid State Chemistry, vol. 182, no. 10, pp. 2598-2601, 2009. 

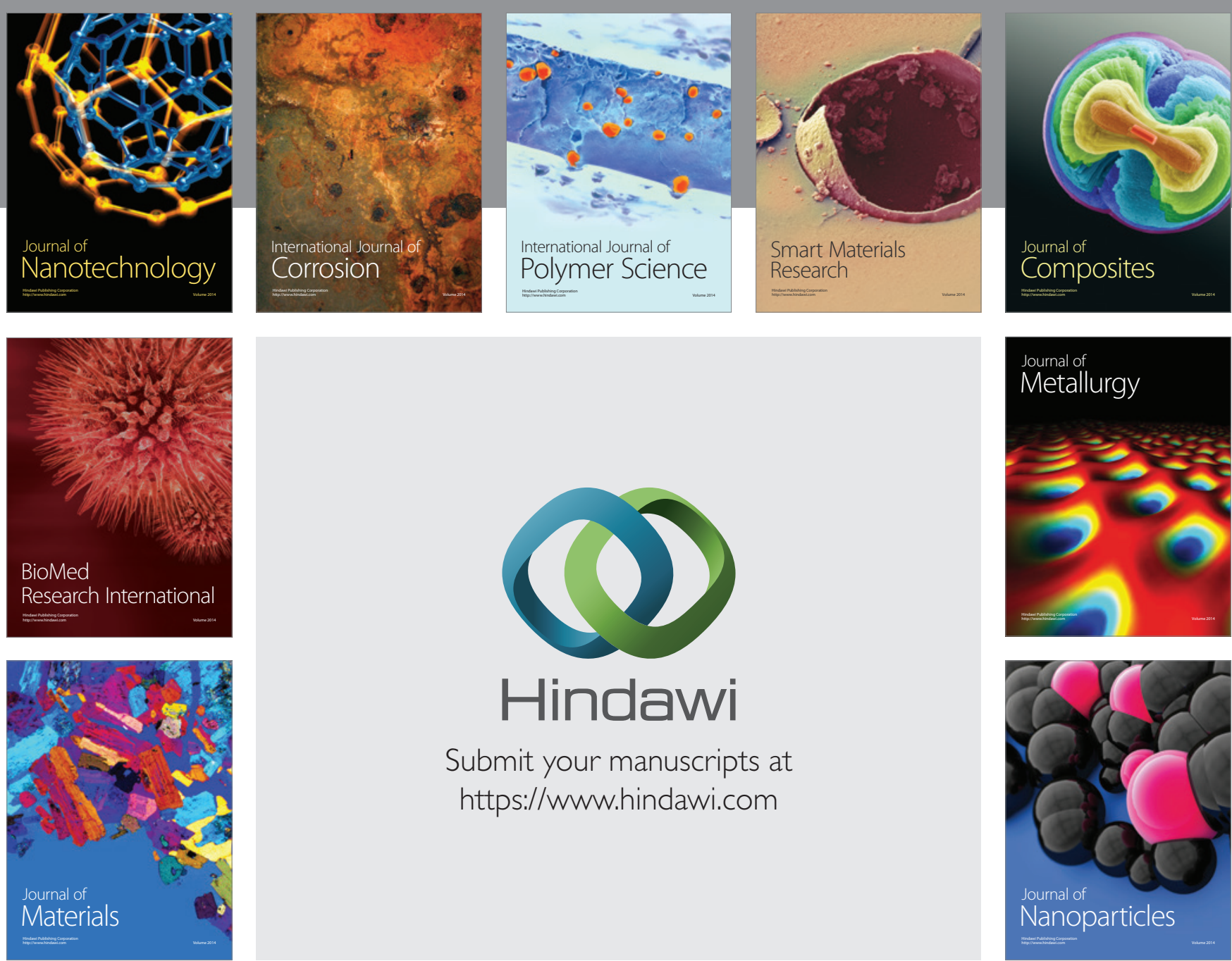

\section{Hindawi}

Submit your manuscripts at

https://www.hindawi.com

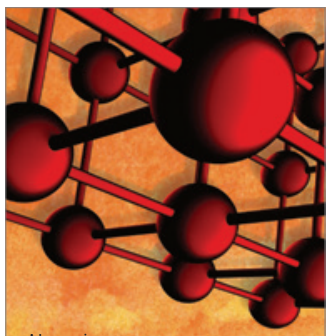

Materials Science and Engineering
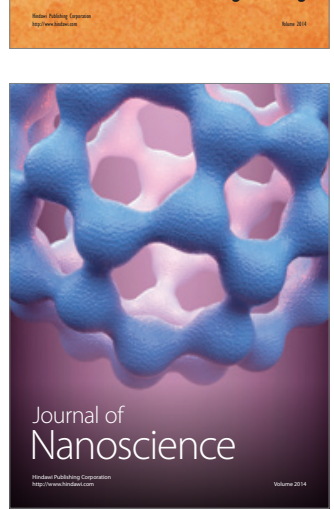
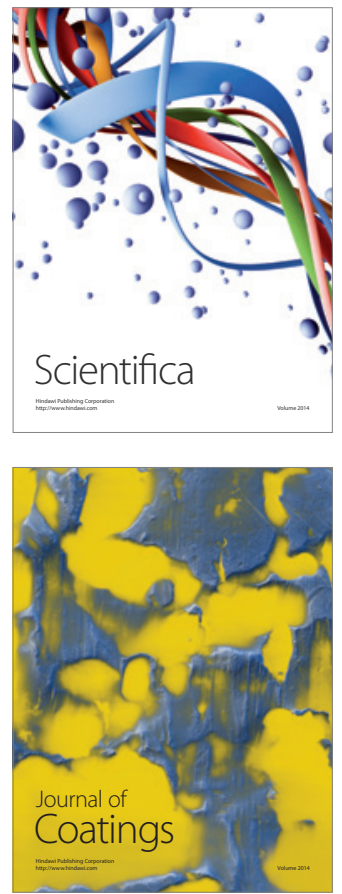
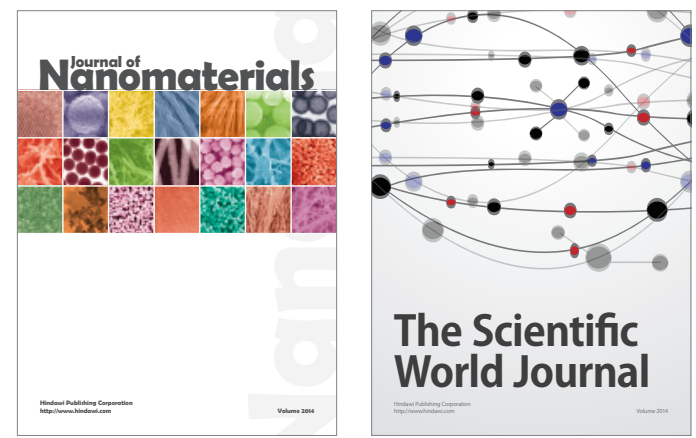

The Scientific World Journal
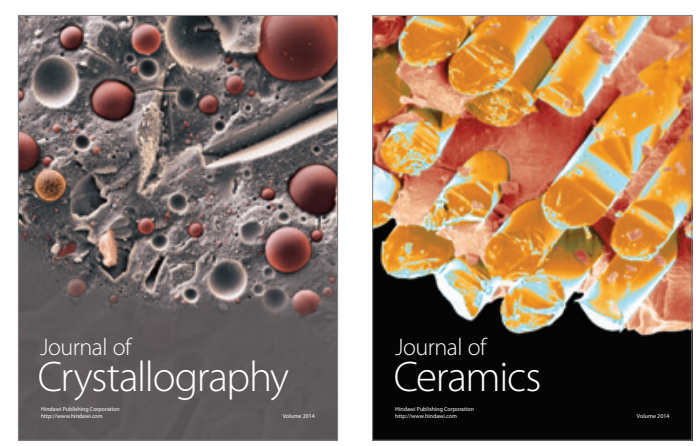
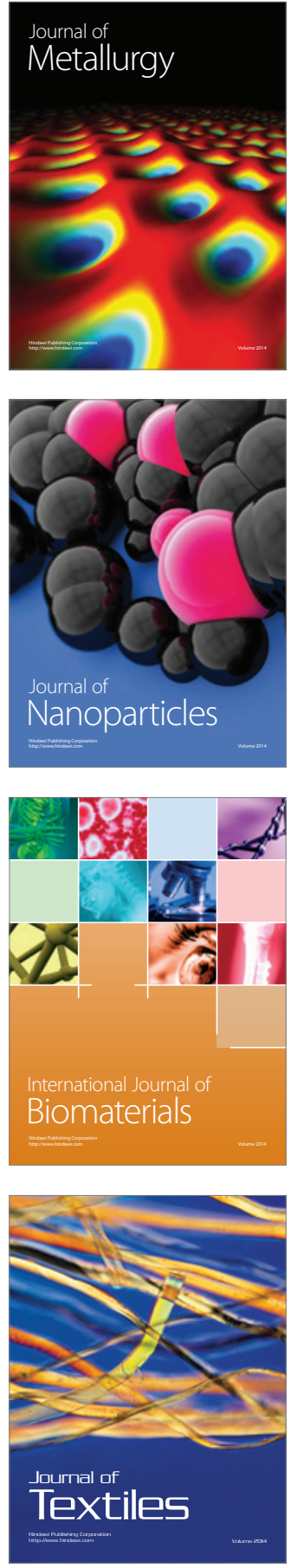